\title{
Student selection process effectiveness: Correlations between task performance and undergraduate success
}

\author{
Catherine Hughes, Helen Gremillion, Geoff Bridgman, Paul Ashley and David McNabb, \\ Unitec, New Zealand
}

\begin{abstract}
INTRODUCTION: This article is a case study of student selection process effectiveness in an undergraduate social work degree at Unitec in Auckland, Aotearoa New Zealand. Addressing an internationally under-researched topic, it examines whether admitted candidates' performance on selection day tasks correlate with their success in the programme.

METHODS: Applicant selection data were analysed for 2012 and 2013 cohorts $(N=196)$. Student success is measured in relation to outcomes across eight courses, considering both course completions and grades received. Correlational analyses were performed to address the research aim. The project also examined whether existing demographic data correlate with success, as these data represent potentially confounding variables.
\end{abstract}

FINDINGS: Performance on selection activities conducted as part of application to this degree does not correlate with course completions, and correlates only moderately with higher grades received for courses. Findings also show that students who are wage-earning or self-employed on admission, studying full time, and/or admitted well before their studies begin are more likely to succeed. No other demographic factors are correlated with student success.

CONCLUSIONS: This study supports existing literature documenting the ineffectiveness of selection criteria for social work programmes, and also addresses a gap in scholarship by examining the value of specific selection tools and measures. Factors that do correlate with student success suggest that being well-resourced as a student is paramount. Supporting students to succeed during the course of their study may be of higher value than attempting to select "suitable" students in the first place.

KEYWORDS: social work; education; selection; admission; Māori; Pacific Island

AOTEAROA

NEW ZEALAND SOCIAL WORK 29(4), 32-48.

CORRESPONDENCE TO: Catherine Hughes chughes2@unitec.ac.nz

\section{Introduction}

This article describes a case study of selection task effectiveness for an undergraduate social work degree at Unitec in Auckland, Aotearoa New Zealand. It addresses gaps in the literature identified in a 2016 international literature review (Hughes, McNabb, Ashley, McKechnie, \& Gremillion, 2016) conducted by a team of co-authors which includes four of the authors involved in the current study. This literature review sought to determine whether social work programmes are using effective tools to select students who will subsequently succeed, or whether there is little or no predictive reliability in the selection process. Key findings include the following:

...there is no simple formula for selecting students who will go on to complete their social work programme, and... many 
of the tools used during the selection process are unreliable predictors of eventual student success. Findings also indicate that existing research is limited; further research is needed, particularly on the value of specific selection tools and measures. (Hughes et al., 2016, p. 94)

In addition, Hughes at al. (2016) found that student success in social work programmes internationally may depend on a complex set of factors including professional socialisation. Professional socialisation is regarded as the assimilation of knowledge, values and skills pertaining to a profession into an individual's identity during their course of study (Cornelissen \& van Wyk, 2007). These findings, coupled with the fact that certain selection measures "such as GPAs from previous academic study have been consistently shown ... to exclude suitable students from programmes" (Hughes et al., 2016, p. 104), provide the motivation for the present project.

The authors of this case study are staff members in the social work programme at Unitec who have regularly taken part in selection processes since the current version was instituted in 2011. We were initially prompted to collect data on and review our selection processes because, while they are time-consuming and resource-heavy, we have had up until now no reliable information about the efficacy of the selection tools currently utilised. An external driver reinforcing the need for review of applicant selection is the expectation that many graduates will gain registration with the Aotearoa New Zealand (ANZ) registration body: the Social Workers Registration Board (SWRB). Internal drivers to review applicant selection include: meeting Unitec's goals for success and retention of target groups including Māori and Pacific Island students, as well as students under the age of 25 , and the long-standing and ongoing desire to select students who are ultimately suitable for practice. This latter point raises a number of questions and tensions, addressed in the following section.

\section{The regulation of social work education in Aotearoa New Zealand}

Apaitia-Vague, Pitt, and Younger (2011) point to a central contradiction surrounding efforts to admit students to social work programmes who will succeed and be fit to practise: a need for "accountability to clients to ensure that workers are safe to practice, and social work values such as inclusion, social justice, the right to education, and a belief in the power of transformative change" (Hughes et al., 2016, p. 103; see also Dillon, 2007; Pelech, Stalker, Regehr \& Jacobs, 1999; Sowbel, 2012). How can admission criteria help ensure student success, without screening out potential students who may succeed in programmes when given the proper support and encouragement? While a detailed consideration of the latter is beyond the scope of the present study, this question points to the importance of critically examining selection processes to ensure that they make a difference in relation to the suitability of students selected, keeping in mind a burden on programmes to scaffold learning for cohorts that include a range of abilities, backgrounds and constraints.

Writing in 2003, Nash (2003) noted the tensions and, at times, competing priorities amongst social work as a profession, the state, social service providers, and social work educators. Arguably these tensions have increased over time, considering market-driven pressures encouraging higher student numbers as well as increasing interest in social work professionalisation, both of which highlight the need for wellqualified graduates. Notably, social work as a profession was recently removed from the Long-Term Skills Shortage list of the New Zealand government. The number of graduates from social work programmes in Aotearoa New Zealand has increased in recent years with the latest figures indicating a corresponding increase in the number of applications for SWRB registration: from 542 in 2013/2014, to 666 in 2014/2015, to 737 in 2015/2016 (SWRB, 2015-2016). 
Although social work registration is not yet mandatory, a paper presented to the Cabinet Social Policy Committee in May 2017 provided several proposals to fulfil the intent of a Social Services Select Committee's recommendation for legislative changes which include the move to mandatory registration over the next two years (Office of the Minister for Social Development, 2017). The minister's proposal to cabinet follows on from a report of the Social Services Committee: an "Inquiry into the Operation of the Social Workers Registration Act 2003" presented to the House of Representatives in December 2016. The report discussed mandatory registration, competence and other prerequisites for registration, fitness to practise, oversight of social workers, complaints assessment committees, the social workers' complaints and disciplinary tribunal, suspending and cancelling practising certificates, and registration (Social Services Committee, 2016).

The 2016 Social Services Select Committee was set up to review the Social Workers Registration Act 2003 (SWR Act) and report back to government. In March 2017, government responded and acknowledged the case being made by the committee for increased regulation of social workers. Between February and April 2017, further work was conducted; a summary of main points notes the recommendations to pursue mandatory registration and protection of title, and to put in place an efficient regulatory regime. As well, the summary mentions additional support to improve the quality and professionalism of social work services as a requirement. ${ }^{1}$

After reviewing the options outlined in the Select Committee's report to government and the government's response documents, the Minister for Social Development determined a preferred option that would extend the coverage of the regulatory regime, but not to the extent suggested by the SWRB. Under this option, only registered social workers would be able to use the title "social worker." This tightening of title use would mean that approximately two thousand currently employed, unregistered, social workers would need to become registered or leave their employment. Social workers would need to be registered as opposed to registrable. The Select Committee proposed that these changes would result in an economy of scale thereby reducing costs for registration (Ministry of Social Development, 2017). The committee's discussion of licensing the roles and tasks of social work resulted in a recommendation that task-based licensing not be supported, as it would not only limit the work currently done by social workers but also shut out other practitioners who may need to carry out some of the roles and tasks of social work.

According to the Ministry of Social Development (2017), preparation for mandatory registration has raised concerns about the quality of training being provided in social work education. Additional accountability and oversight of educators has been recommended as part of the legislative change to the SWR Act. In a mandatory environment, employers will be seeking only those employees who are registered at the completion of their tertiary study. This fact, alongside protection of title, has major implications for student selection as there are ethical tensions surrounding the admission of students who may not meet the criteria for registration. If students are ineligible for social work registration, they will not be eligible for employment as social workers.

One of the reasons for social work graduates not gaining registration is failure to meet the requirements of current fit and proper criteria, a somewhat subjective determination based on several factors including a history of previous convictions (SWRB, 2015). However, to improve the transparency of the fit and proper criteria, Cabinet have:

propose[d] that the SWR Act adopt a similar approach to the HPCA Act and provide a more comprehensive list of the factors the Board can consider in the exercise of its discretion (including an assessment of any mental or physical 
health issues and disciplinary history). (Office of the Minister for Social

Development, 2017, p. 11)

It remains to be seen whether the factors that can be considered will allow applicants to gain access to social work training with some certainty of their eligibility to gain registration, or will further exclude applicants with potential who will therefore be ineligible for registration.

Contemporary social work education remains a contested site in the wider political context and within the profession itself (Beddoe, 2014). The SWRB reviewed its expectations for social work programmes over 2012-2013 and created a new minimum level of a four-year undergraduate programme for all tertiary providers (SWRB, 2013). This requirement was fought by Unitec and other tertiary providers on the grounds that many three-year degrees were robust, and that economically disadvantaged students should not have to pay for a further year's study when other options such as employer-funded internships and post-graduate study were possible (McNabb, 2014). The latter concern is heightened by the recent introduction of limitations to student funding for loans and allowances (Ministry of Social Development, 2013). These tensions surrounding accessibility of social work education and eligibility for registration highlight the importance of both appropriate and fair student selection criteria and adequate study support systems and processes.

\section{Indigenous populations}

Two of the priority groups identified by Unitec are Māori and Pacific Island students. Boosting Māori and Pasifika student success is also part of the New Zealand Government's Tertiary Education Strategy (Ministry of Education and the Ministry of Business, Innovation and Employment, 2014). As Hughes et al. (2016) note, there is a paucity of research, both internationally and in Aotearoa New Zealand, on the selection of indigenous populations for social work training.
Considering a commitment in Aotearoa New Zealand to Te Tiriti o Waitangi and to Māori as a priority group for tertiary education, as well as the profession's requirement to ensure that Māori are represented in student cohorts, it is somewhat surprising that there has been no specific research on selection of Māori for social work education. Curtis, Wikaire, Stokes, and Reid (2012) did, however, include social work more broadly in their review of health workforce inequalities in Aotearoa New Zealand. Their findings include the need for programmes to support Māori student success in a culturally appropriate manner. The state responded to the limited success of Māori in education by initiating Ka Hikitia: Accelerating Success 2013-2017, building on an earlier policy strategy, which saw participation rates for Mãori aged 18-24 years in Bachelor degrees increase from 21\% in 2007 to $28 \%$ in 2012 (Ministry of Education, 2013). However, participation rates since 2012 appear to have decreased slightly (Ministry of Education, 2017) - although it is difficult to compare reports using a range of measures.

The Pasifika Education Plan has seen a similar overall increase in Pasifika enrolments from 14\% in 2011 to $15 \%$ in 2012 (Horrocks, Ballantyne, Silao, Manueli, \& Fairbrother, 2012). However, updated information is lacking, as is information on completion rates for, as well as selection of, these students. It is noteworthy that there are significant pressures on Pasifika students including high parental expectations and aspirations (Madjar, McKinley, Jensen, \& Van Der Merwe, 2009), which Greenwood and Te Aika (2009) note exist for Māori students as well. A report by the Ministry of Education (2009) found that family expectations and commitments more generally, including child care responsibilities, disproportionally affect Pasifika students (see also Madjar et al., 2009), with implications for time and energy to focus on tertiary studies.

As noted in Hughes et al. (2016, p. 102) and the point is also applicable to Pasifika students (see Horrocks et al., 2012): 
Existing literature on Māori student experiences and success focuses on recruitment and retention, not selection processes. Such a focus is arguably appropriate in the current environment, in which there are efforts to create programmes that are successful for Māori, rather than fit Māori students into existing programmes (see Beddoe, 2007). It remains to be seen whether certain selection criteria are relevant specifically for the admission of Māori students who will be successful in social work programmes. (Hughes et al. 2016, p. 102)

\section{The Bachelor of Social Practice degree at Unitec}

\section{Background and student success and retention}

The Bachelor of Social Practice (BSP) degree at Unitec was established in 1992. Until 2015 students enrolled in a three-year programme (if undertaken full time) providing a social work registrable qualification. At the start of 2014, when data entry for this study began, the BSP programme included 357 Effective Full Time Students (EFTS) and 22 Full Time Equivalent (FTE) staff (who also taught across two small postgraduate programmes provided by the Social Practice Department).

The following information includes figures from 2014, when students whose data are included in this research were still studying on the degree. The BSP programme consists of a range of assessment methods that are not exam-based, and is made up of mainly full-time students $-90 \%$ of its EFTS. The programme enjoys $90 \%$ success (passed course) and $93 \%$ retention (re-enrolled in the following semester) rates (Social Practice, 2015). As noted above, two key target groups are Māori and Pacific students. Māori students in the programme have an $86 \%$ success rate and a $90 \%$ retention rate. Pacific students have an $86 \%$ success rate and a $91 \%$ retention rate. Graduate employment figures overall exceed $80 \%$ in the year following graduation, which compares favourably to other professional degree programmes across Unitec.

\section{Selection day activities and scoring}

Selection day (SD) activities for admission into the BSP degree include an individual interview, a team activity and a writing task. The activities chosen for SD reflect the nature of assessment used in the degree; written assessment, group presentations, and individual assessment in work-based activities. These activities are described in more detail below. Applicants are given a score out of five on each activity, with "one" indicating the lowest possible score and "five" the highest, so that the total maximum score an applicant can receive is 15 .

Once the applicants have left on SD, staff hold a review meeting where scores for all activities are recorded and archived on the SD spreadsheet. Most selection decisions are made at that meeting, and if follow-up is required, the Programme Leader gains clarity from staff about the areas of concern. Applicants are placed in one of four initial categories: accept, require more information, waitlist, and decline.

Except in exceptional circumstances, applicants with a combined score of eight or below are not admitted. For applicants who score above eight, additional criteria are taken into consideration as well: particularly the nature and date of any convictions (discussed below), and reference feedback.

\section{Interviews}

Individual, 10-15 minute interviews are carried out in pairs including a Social Practice staff member and, when possible, a community volunteer affiliated with a fieldwork placement agency. The score for the interview is based on candidate responses to the following questions:

- Can you tell me why you are interested in studying in the Social Practice programme?

- What do you understand about social justice? 
- Why do you think we have a commitment to biculturalism at Unitec?

- Do you think it is important for social workers to know about the Treaty of Waitangi? Why?

Notes are taken and, after the interview, the two interviewers negotiate a mark out of five for the candidate's answers. If negotiation fails, the candidate is given the average of the two marks.

\section{Team activity}

The team activity is a group discussion of a provided scenario in which several of the characters take actions resulting in a man being murdered. This activity is used to assess the five applicant attributes listed below. Applicants are asked in groups of six to rate the characters in the scenario in terms of culpability or innocence. They must present as a team and are given marks individually on their participation. Staff members observe the group discussions and score individuals for each of the following criteria:

- maturity, motivation and resilience;

- vulnerability awareness;

- interpersonal understanding; open and non-judgmental attitudes;

- $\quad$ self confidence;

- analytical ability, conceptual thinking, task focus.

Although applicants tend to think they are being marked on contribution content, they are actually being scored on their involvement in, and contribution to, the discussion. Staff members negotiate or average their total scores per applicant, then divide the total by five to produce a final mark.

\section{Writing task}

The writing task is conducted in a computer lab under examination conditions. Candidates are given a temporary login to the institute's shared drives and are asked to create a word document. They are given a hard copy of a written exercise and 15 minutes to read it carefully. Marking criteria are explained to the candidates, who are then given 20 minutes to write their response to the question, 'How might you respond to a social issue' described in the handout. At the end of the 20 minutes, candidates are asked to "save as" their document and to log off.

The writing task is scored according to the following criteria: structure, logic and academic presentation. Two staff members mark the written work and negotiate or average a final agreed mark.

Table 1: Selection Day Scores

Mean, median and standard deviations for the three selection day tasks team activity interview writing task total

\begin{tabular}{|l|l|l|l|l|}
\hline mean & 4.76 & 4.45 & 3.80 & 13.01 \\
\hline median & 5.0 & 4.5 & 4.0 & 13.0 \\
\hline $\begin{array}{l}\text { standard } \\
\text { deviation }\end{array}$ & 0.59 & 0.71 & 0.95 & 1.38 \\
\hline
\end{tabular}

Table 1 shows that the team activity has the highest scores and the least variability while the writing task has the lowest scores and the most variability.

\section{Measures of success in the programme}

Success in the programme is measured in terms of course completions and grades received across eight compulsory courses in Year One of the BSP degree (totalling 120 credits, or one year's full-time study). Overall student GPA across these eight courses is an additional data point per student. People-Soft, the student management program at Unitec, was used to access academic transcripts.

All courses that students completed were marked with scores ranging from $\mathrm{A}+$ to $\mathrm{E}$ (fail grade). Each letter grade was assigned a corresponding numerical mark at the midpoint of the numerical range that a given letter grade represents. A non-completion mark of " 0 " was assigned when a course 
grade was DNC (did not complete), W (withdrawn), or blank (did not enrol in a course, though admitted to the programme). Cross credits $(0.05 \%$ of the total) were awarded a B grade.

Figure 1 shows all the GPA (0-100) data broken down by course. Grade averages range from 75.4 for Whanaungatanga, Gender \& Social Practice to 54.7 for Discourses of Social Practice, with the overall GPA being 63.1.

\section{Other measures}

Enrolled students provide additional information which we included in our analyses, as these data represent potentially confounding variables. We examine whether the following are correlated with student success: age, gender, culture, conviction history, mental health or disability issues, date of intake, full- or part-time student status, and work status immediately prior to enrolment. The latter is comprised of three groups of students: from school or tertiary education; wage-earner/self-employed; or unemployed, not employed, or beneficiary. Gender are categorised as "man" or "woman": Unitec data do not include transgender or "other" identifications. Culture is comprised of four categories: Māori, Pacific Island, Pākehā/

GPA (out of 100), incl. and excl. non-completions

average grade incl. dropouts a average grade after removal of drop outs

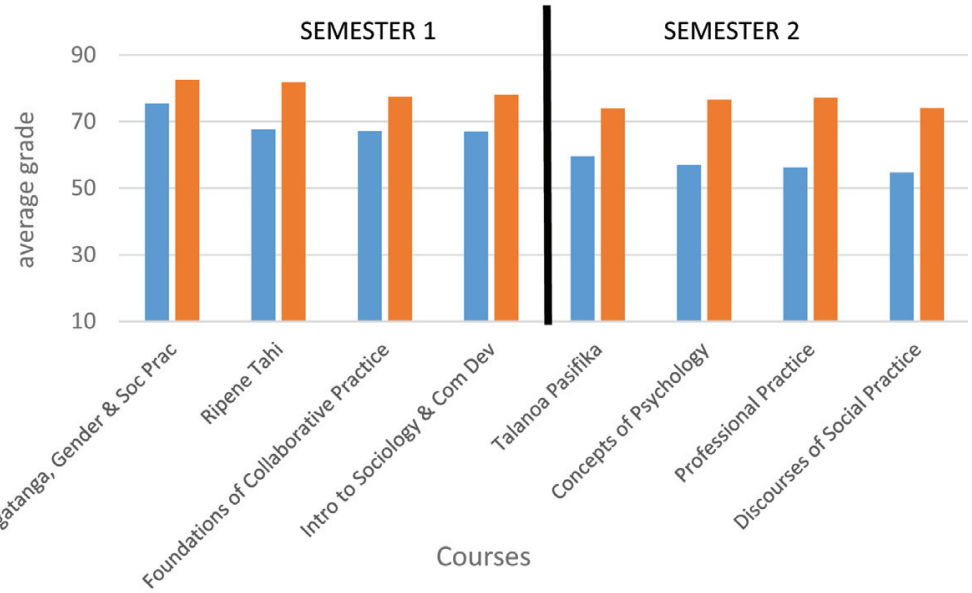

Figure 1. GPA (out of 100) including and excluding non-completions.
European, and African/Asian. African and Asian students comprise a single category for analysis purposes because of relatively low numbers within each of these cultural groupings. November intakes (for those starting the degree in February of the following year) - our largest intakes - are separated out from the "top-up" intake dates taking place during the year of enrolment, and the latter are combined into one group.

Conviction histories are taken from a required applicant report and confirmed by a police check procedure. Convictions range from a few serious charges such as assault, theft and fraud through to trespass, drunk in charge of a vehicle and minor driving offences. Candidates are asked to declare any mental health issues, which include depression, anxiety, and the effects of trauma. These are not necessarily diagnoses, and indeed include at times significant signs of distress, confusion, or disconnection noted by Social Practice staff members during SD tasks, and reported during the SD review meeting. Note that conviction histories and mental health and disability issues were recorded for students admitted in $2012(N=150)$, and were not recorded for students admitted in 2011 (46 students).

\section{Methodology}

\section{Research aim}

To determine whether performance on selection day (SD) activities is correlated with student success in the Bachelor of Social Practice degree.

As noted above, this project also examined whether certain demographic variables correlate with success, as these variables are potentially confounding ones in relation to our research aim.

\section{Sample}

Applicant selection and demographic data were collected for three cohorts entering the programme in 2012 (November 2011, January/February 2012 and mid-year 2012 
intakes) and for one cohort entering in 2013 (November 2012 intake). All students admitted during this time, including those who withdrew from the programme or did not complete particular courses, were included as participants $(N=196)$. All participants, including those enrolled part-time, had ample opportunity to complete all eight courses included in the analysis before data entry for this project was complete.

\section{Ethical considerations}

Ethics approval is not required at Unitec for projects such as this one, entailing analysis of de-identified programme data for a secondary (research) purpose. On the advice of Unitec's Research Ethics Committee chair, we consulted Unitec's legal counsel to ensure that publication of our findings would protect student privacy. This latter was confirmed: no students are identifiable, even to themselves (no findings relate to sub-groups of students smaller than 20), and legal constraints surrounding the secondary use of data do not apply in this case, as no identifiable personal information is reported.

A rigorous process was followed in the handling of the project data to preserve participants' confidentiality, as per standard procedure for any evaluative analysis within Social Practice. First, student names were removed from all pieces of data. In her role at the time as Programme Leader, the first author (Hughes) had access to student grades in the normal course of her work, so she undertook the task of removing student names from transcripts. Next, in the process of entering the data into a spreadsheet, student ID numbers only were used by two research team members strictly for the purpose of linking together the different pieces of data per (un-named) student. Finally, prior to data analysis, student ID numbers were permanently removed from the collated data set, rendering the data fully un-identifiable.

\section{Data analysis and findings}

\section{Non-completions and student success}

Analysis of grades received revealed the salience of a particular group of students: those who failed to complete one or more courses. Failing to complete a compulsory course by withdrawing after $75 \%$ of the course has been taught, or failing to submit work, clearly indicates lack of success and results in a Did Not Complete (DNC) grade being awarded and a failing GPA. Of the 1568 opportunities (196 students $\times$ eight courses) to pass a course, a full $18.9 \%$ of them resulted in non-completion. A pass grade occurred for $78.8 \%$ of course opportunities, leaving only $2.3 \%$ for failures occurring due to the poor quality of assignment work submitted.

In order to isolate the effects on our findings of the large group (79 students) who did not complete one or more courses, we examine correlations between selection day performance and grades received both with this group included and excluded from the analyses performed. Amongst the group who completed all eight courses are a small number of students (nine) who had failing GPAs after submitting all required work for all eight courses. Note that non-completion and failure rates here do not equate with the attrition rate in the programme: a number of students who did not complete one or more courses, or failed one or more courses after submitting work for them, are eligible to re-enrol in these courses in the future. Most students who did not complete one or more courses did complete several courses; only nine students who enrolled in all eight compulsory courses did not complete any of them.

The justification for isolating the noncompletion group is that nearly $90 \%$ of failing GPAs in our analysis are due to non-completion. This fact accounts for much of the difference between semester one and semester two grade averages shown in Figure 1 (a 12.4-point difference, $p<0.00$ vs. a 4.7-point difference, $p<0.00$ when non-completions are excluded). 


\section{QUANTITATIVE RESEARCH}

Table 2: Correlation Coefficients for All Students

\begin{tabular}{|c|c|c|c|c|c|c|}
\hline \multicolumn{7}{|c|}{$\begin{array}{l}\text { Correlation coefficients }(r) \text { of age, gender and culture with course grades for all students, including those who did not complete } \\
\text { courses }(N=196) \text {. }\end{array}$} \\
\hline Courses & $\begin{array}{c}\text { age } \\
\text { (mean = 35.6; } \\
\text { range = 20-64) }\end{array}$ & $\begin{array}{c}\text { gender } \\
\text { (woman +; } \\
N=169,82 \% \text { ) }\end{array}$ & $\begin{array}{c}\text { Pacific } \\
\text { Island } \\
(N=48 ; 24 \%)\end{array}$ & $\begin{array}{c}\text { Maori } \\
(N=38 ; 19 \%)\end{array}$ & $\begin{array}{c}\text { Pākehā/ } \\
\text { European } \\
(N=69 ; 35 \%)\end{array}$ & $\begin{array}{c}\text { African/ } \\
\text { Asian } \\
(N=41 ; 21 \%)\end{array}$ \\
\hline 1. Ripene Tahi & 0.05 & -0.04 & -0.05 & 0.04 & -0.05 & 0.08 \\
\hline $\begin{array}{l}\text { 2. Whanaungatanga, Gender and Social } \\
\text { practice }\end{array}$ & -0.01 & -0.13 & -0.05 & -0.08 & 0.05 & 0.08 \\
\hline 3. Foundations of Collaborative Practice & 0.00 & -0.02 & $-0.15^{*}$ & -0.02 & 0.09 & 0.07 \\
\hline $\begin{array}{l}\text { 4. Introduction to Sociology \& } \\
\text { Community Development }\end{array}$ & 0.00 & -0.03 & -0.07 & -0.03 & 0.01 & 0.09 \\
\hline 5. Concepts of Psychology & 0.01 & 0.08 & -0.07 & -0.03 & -0.04 & $0.14^{*}$ \\
\hline 6. Discourses of Social Practice & 0.04 & 0.05 & -0.06 & -0.10 & 0.07 & 0.08 \\
\hline 7. Professional Practice & 0.08 & 0.06 & -0.09 & -0.12 & 0.04 & $0.16^{*}$ \\
\hline 8. Talanoa Pasifika & -0.04 & 0.00 & 0.02 & -0.13 & 0.03 & 0.07 \\
\hline 1-4: Mean all Semester 1 courses & 0.01 & -0.06 & -0.09 & -0.03 & 0.03 & 0.09 \\
\hline 5-8: Mean all Semester 2 courses & 0.03 & 0.06 & -0.06 & -0.11 & 0.03 & 0.13 \\
\hline 1-8 Mean all Year One courses & 0.02 & 0.00 & -0.08 & -0.07 & 0.03 & 0.12 \\
\hline
\end{tabular}

\section{Success in relation to demographic data}

In the demographic data we collected there are many variables that could influence the grades that students achieve. To eliminate their impacts on the key question of whether intake assessment tasks are correlated with success, we first examine the effects of these demographic variables, both when we include and exclude non-completion cases.

Table 2 shows that, out of 66 correlations of age, gender and culture with course grades, there are only three significant correlations. However, if we use the more stringent criterion for significance of $p<0.01$, none of the data in Table 1 are significant, suggesting that there is no advantage for any age, gender or cultural group in the first-year courses of the BSP degree.

Table 3 repeats the information on Table 2 except that it excludes non-completions.

The profile of this group is very similar in age, gender and culture to the full sample, showing that not completing a course is not related to these demographic features. The pattern of correlations also confirms what is presented in Table 1: there is no relationship between grades obtained and the demographic features. Of the 66 correlations in Table 2, only one is significant.

Table 4 includes non-completion data and explores a second tranche of demographic data. It shows some strong effects on grades from work status at intake, studying fullor part-time, and date of intake. Being a wage earner or self-employed immediately prior to study is correlated significantly with better outcomes on all BSP courses and overall mean grades. The mean grade difference between being a wage earner or self-employed and being either: 1) from school/tertiary education; or 2) unemployed, not employed or on a benefit is 11.7 points -70.0 vs. 58.3. Those who study full time do better than part-time students in six of eight courses and in overall mean grades. Fulltimers, overall, have mean grades that are 13.5 points higher than part-timers ( $66.5 \mathrm{vs.}$ 53.0). Finally, there are different outcomes when comparing the main November intakes (2011 and 2012) and the combined top-up intakes of January, February and mid-year 2012. Students from the top-up intakes do worse than students from the November 
Table 3: Correlation Coefficients for all Students Excluding Non-Completion

\begin{tabular}{|c|c|c|c|c|c|c|}
\hline Courses & $\begin{array}{c}\text { age } \\
\text { (mean = 36.2; } \\
\text { range = 21-64) }\end{array}$ & $\begin{array}{c}\text { gender } \\
\text { (woman +; } \\
N=95,82 \% \text { ) }\end{array}$ & $\begin{array}{c}\text { Pacific } \\
\text { Island } \\
(N=27 ; 23 \%)\end{array}$ & $\begin{array}{c}\text { Maori } \\
(N=20 ; 17 \%)\end{array}$ & $\begin{array}{c}\text { Pākehā/ } \\
\text { European } \\
(\mathrm{N}=41 ; 35 \%)\end{array}$ & $\begin{array}{c}\text { African/ } \\
\text { Asian } \\
(N=29 ; 25 \%)\end{array}$ \\
\hline 1. Ripene Tahi & 0.03 & 0.00 & 0.11 & 0.04 & -0.18 & 0.05 \\
\hline $\begin{array}{l}\text { 2. Whanaungatanga, Gender and Social } \\
\text { Practice }\end{array}$ & 0.10 & -0.09 & 0.15 & -0.10 & 0.01 & -0.07 \\
\hline 3. Foundations of Collaborative Practice & 0.05 & 0.02 & -0.05 & -0.15 & 0.07 & 0.10 \\
\hline $\begin{array}{l}\text { 4. Introduction to Sociology \& Community } \\
\text { Development }\end{array}$ & 0.00 & 0.08 & 0.02 & -0.10 & 0.00 & 0.07 \\
\hline 5. Concepts of Psychology & 0.07 & 0.09 & 0.10 & -0.16 & -0.14 & 0.20 \\
\hline 6. Discourses of Social practice & 0.12 & 0.20 & -0.19 & -0.03 & 0.21 & -0.02 \\
\hline 7. Professional Practice & 0.04 & 0.10 & 0.00 & $-0.25^{*}$ & 0.06 & 0.15 \\
\hline 8. Talanoa Pasifika & 0.06 & 0.01 & 0.08 & -0.12 & -0.04 & 0.06 \\
\hline 1-4: Mean all Semester 1 courses & 0.06 & 0.14 & 0.14 & 0.03 & -0.01 & -0.15 \\
\hline 5-8: Mean all Semester 2 courses & 0.10 & 0.19 & 0.00 & -0.15 & 0.05 & 0.07 \\
\hline 1-8 Mean all Year One courses & 0.09 & 0.13 & 0.04 & -0.15 & 0.01 & 0.07 \\
\hline
\end{tabular}

Table 4: Work Status and Course Grades

Correlation coefficients $(r)$ of work status at intake, being full-time and date of intake with course grades for all students, including those who dropped out of courses $(N=196)$.

Work status at intake

Courses

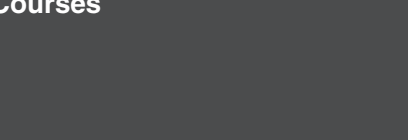

From

school or

tertiary ed.

$(N=63,32 \%)$ \begin{tabular}{l|l|r} 
Wage & Unemployed, full time
\end{tabular} earner/selfemployed

not employed $(N=147 ; 75 \%)$ or beneficiary

$(N=53 ; 27 \%)$
Date of intake

Nov 2011 Jan/Feb \& Nov 2012 $(N=46 ; 23 \%)$ midyear $2012(N=79 ; 40 \%)$ $(N=71 ; 36 \%)$

\begin{tabular}{|c|c|c|c|c|c|c|c|}
\hline 1. Ripene Tahi & $-0.15^{*}$ & $0.22 \#$ & -0.08 & $0.22 \#$ & -0.03 & $-0.15^{*}$ & $0.17^{*}$ \\
\hline $\begin{array}{l}\text { 2. Whanaungatanga, Gender and } \\
\text { Social Practice }\end{array}$ & -0.06 & $0.22 \#$ & $-0.17^{*}$ & $0.22^{\wedge}$ & 0.00 & -0.07 & 0.06 \\
\hline $\begin{array}{l}\text { 3. Foundations of Collaborative } \\
\text { Practice }\end{array}$ & -0.04 & $0.15^{\star}$ & -0.13 & $0.19 \#$ & 0.02 & $-0.28^{\wedge}$ & $0.26^{\wedge}$ \\
\hline \begin{tabular}{|c|c|} 
4. Introduction to Sociology \& \\
Community Development
\end{tabular} & -0.09 & $0.21 \#$ & $-0.14^{*}$ & $0.17^{*}$ & -0.01 & $-0.23^{\wedge}$ & $0.24^{\wedge}$ \\
\hline 5. Concepts of Psychology & 0.01 & $0.14^{*}$ & $-0.16^{*}$ & 0.11 & 0.04 & $-0.23^{\wedge}$ & $0.19 \#$ \\
\hline 6. Discourses of Social Practice & 0.00 & $0.19 \#$ & $-0.21 \#$ & $0.19 \#$ & 0.08 & -0.13 & 0.06 \\
\hline 7. Professional Practice & -0.01 & $0.21 \#$ & $-0.22^{\wedge}$ & 0.14 & 0.08 & $-0.22^{\wedge}$ & $0.15^{\star}$ \\
\hline 8. Talanoa Pasifika & 0.01 & $0.15^{\star}$ & $-0.17^{*}$ & $0.30^{\wedge}$ & 0.13 & -0.03 & -0.08 \\
\hline 1-4: Mean all Semester 1 courses & -0.10 & $0.23^{\wedge}$ & $-0.15^{*}$ & $0.23^{\wedge}$ & -0.01 & $-0.21 \#$ & $0.21 \#$ \\
\hline 5-8: Mean all Semester 2 course & 0.00 & $0.20 \#$ & $-0.22^{\wedge}$ & $0.21 \#$ & 0.09 & $-0.18 \#$ & 0.10 \\
\hline 1-8 Mean all Year One courses & -0.05 & $0.23^{\wedge}$ & $-0.20 \#$ & $0.23^{\wedge}$ & 0.05 & $-0.21 \#$ & $0.16^{*}$ \\
\hline
\end{tabular}

Note. ${ }^{*}=p<0.05, \#=p<0.01 ; \wedge=p<0.005$ (two-tailed), i.e., this is a significant correlation either positive or negative with the chance of error being less than $5 \%, 1 \%$ and $0.5 \%$, respectively. 


\section{QUANTITATIVE RESEARCH}

Table 5: Work Status and Course Grades-Non-Completions Removed

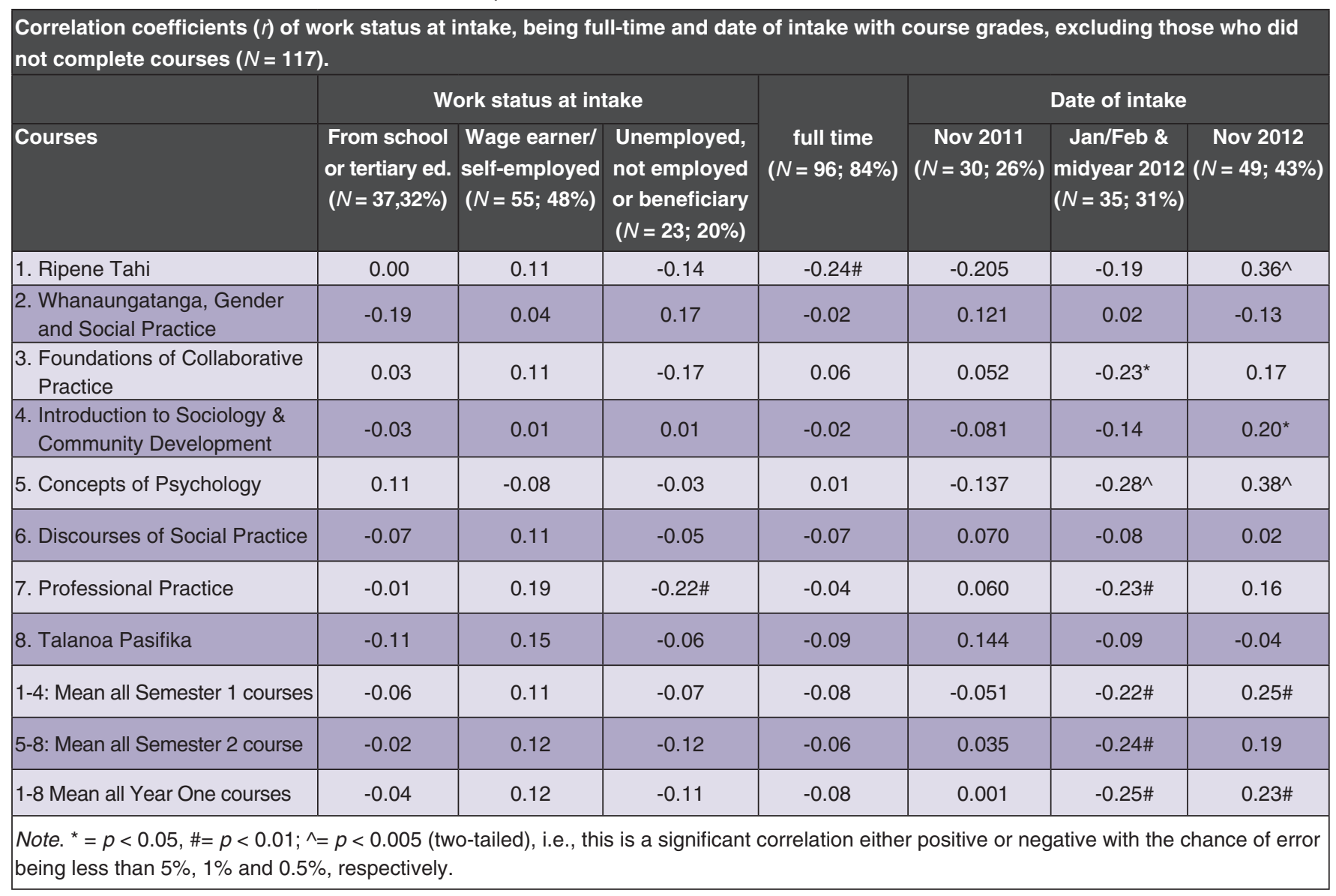

intakes in five courses and overall - mean grade $=56.0$ vs. $65.4($ Nov 2011) and 68.0 (Nov 2012). These three effects - work status at intake, studying full-time and date of intake - are independent of each other as none of the inter-correlations between them are significant.

When non-completions are removed from the data (see Table 5), work status at intake and being full time no longer have a significant impact on grades, with only two significant correlations. However, intake date still impacts on grades for the same five courses as shown in Table 4, and overall there is still a significant disadvantage associated with enrolling in top-up intakes (mean grade $=77.4$ vs $80.6, p<0.01$ ) . These findings indicate that being employed at intake and being a full-time student are associated with success only when we consider the entire sample (including noncompletions). Unlike the effect of intake in November, they are not associated with degree of success for students who completed all eight courses.

There are two remaining demographic features to consider: any record of convictions and mental health issues. While these factors have moderate-to-strong correlations with a few other demographic features, neither correlate significantly with student success.

We are now in a position to examine the effect on student success of selection day (SD) scores. Table 6 shows that total SD scores and the writing task influence the degree of success for students who complete 
Table 6: Selection Day Scores and Student Success

\begin{tabular}{|c|c|c|c|c|c|c|c|c|}
\hline \multirow[b]{2}{*}{ Courses } & \multicolumn{4}{|c|}{ Non-completions included $N=196$} & \multicolumn{4}{|c|}{ Non-completions excluded $N=117$} \\
\hline & $\begin{array}{c}\text { team } \\
\text { activity }\end{array}$ & interview & $\begin{array}{c}\text { Writing } \\
\text { task }\end{array}$ & $\begin{array}{l}\text { total } \\
\text { score }\end{array}$ & $\begin{array}{c}\text { team } \\
\text { activity }\end{array}$ & interview & $\begin{array}{c}\text { Writing } \\
\text { task }\end{array}$ & $\begin{array}{l}\text { total } \\
\text { score }\end{array}$ \\
\hline 1. Ripene Tahi & -0.03 & 0.04 & -0.08 & -0.05 & 0.134 & $0.224^{*}$ & -0.018 & 0.146 \\
\hline 2. Whanaungatanga, Gender and Social Practice & -0.14 & 0.06 & -0.11 & -0.11 & -0.204 & 0.104 & -0.018 & -0.055 \\
\hline 3. Foundations of Collaborative Practice & -0.05 & 0.10 & -0.04 & 0.01 & 0.075 & 0.173 & 0.181 & $0.241 \#$ \\
\hline 4. Introduction to Sociology \& Community Development & 0.02 & 0.07 & -0.11 & -0.03 & -0.037 & 0.093 & $0.183^{*}$ & 0.158 \\
\hline 5. Concepts of Psychology & 0.05 & 0.06 & -0.11 & -0.03 & 0.004 & $0.229^{*}$ & 0.130 & $0.199^{*}$ \\
\hline 6. Discourses of Social Practice & -0.01 & $0.12^{*}$ & 0.05 & 0.09 & $0.216^{*}$ & 0.108 & -0.013 & 0.133 \\
\hline 7. Professional Practice & -0.06 & 0.07 & -0.05 & -0.03 & 0.072 & 0.033 & $0.366^{\wedge}$ & $0.312^{\wedge}$ \\
\hline 8. Talanoa Pasifika & -0.03 & 0.07 & 0.10 & 0.10 & 0.055 & 0.126 & 0.151 & $0.191^{*}$ \\
\hline 1-4: Mean all Semester 1 courses & -0.06 & 0.08 & -0.10 & -0.05 & 0.106 & 0.044 & $0.285^{\wedge}$ & $0.273^{\wedge}$ \\
\hline 5-8: Mean all Semester 2 course & -0.01 & 0.09 & -0.01 & 0.04 & 0.160 & 0.108 & $0.269^{\wedge}$ & $0.313^{\wedge}$ \\
\hline 1-8 Mean all Year One courses & -0.03 & 0.09 & -0.05 & 0.00 & 0.105 & 0.168 & $0.230 \#$ & $0.288^{\wedge}$ \\
\hline
\end{tabular}

Table 7: Means of SD Scores

\begin{tabular}{|l|l|c|c|c|c|}
\hline \multicolumn{4}{|l|}{ Means of selection day scores and correlations with intake dates, excluding those who did not complete courses. } \\
\hline Date of intake & team activity & interview & Writing task & total score \\
\hline November $2011(N=30 ; 26 \%)$ & $4.82,0.09$ & $4.65,0.15$ & $4.23,0.31^{\wedge}$ & $13.70,0.33^{\wedge}$ \\
\hline Jan/Feb \& midyear 2012 $(N=35 ; 31 \%)$ & $4.54,-0.22^{*}$ & $4.38,-0.13$ & $3.61,-0.08$ & $12.54,-0.21^{*}$ \\
\hline November $2012(N=49 ; 43 \%)$ & $4.82,0.13$ & $4.49-0.01$ & $3.50,-0.20$ & $12.81,-0.10$ \\
\hline
\end{tabular}

Note. ${ }^{*}=p<0.05, \wedge=p<0.005$ (two-tailed), i.e., this is a significant correlation either positive or negative with the chance of error being less than $5 \%$ and $0.5 \%$, respectively.

all courses, but do not predict success when non-completions are included in the analysis. In the latter case, there is only one significant correlation out of 44 . When non-completions are excluded, however, the writing task and the total intake scores have moderate to strong correlations across a number of courses, and across semester mean grades and overall mean grades. In addition, all the SD tasks positively correlate with the grades for at least one course.

Recall that, unlike any other demographic factor, date of intake also has a significant influence on grades once non-completions are excluded. In addition, there are four significant correlations between intake date and SD scores for students who complete all courses, as shown in Table 7 below.

While other measures in Tables 2-6 have a small number of significant correlations with SD scores when non-completions are excluded (four out of 48 measures at $p<0.05$ ), only $2 / 132(1.5 \%)$ of these measures are significantly correlated with course grades. In contrast, more than $25 \%$ of intake date correlations with both SD scores and 


\section{QUANTITATIVE RESEARCH}

Table 8: Selection Day Scores Without Intake Date Effect

\begin{tabular}{l}
$\begin{array}{l}\text { Correlation Selection Day scores with course grades, excluding those who did not complete courses and after the effect of intake } \\
\text { date has been removed. } \\
\text { Courses }\end{array}$ team activity \\
\cline { 2 - 5 }
\end{tabular}

Mean GPA score for the eight Year 1 courses as a function of the total selection day score, excluding dropouts.

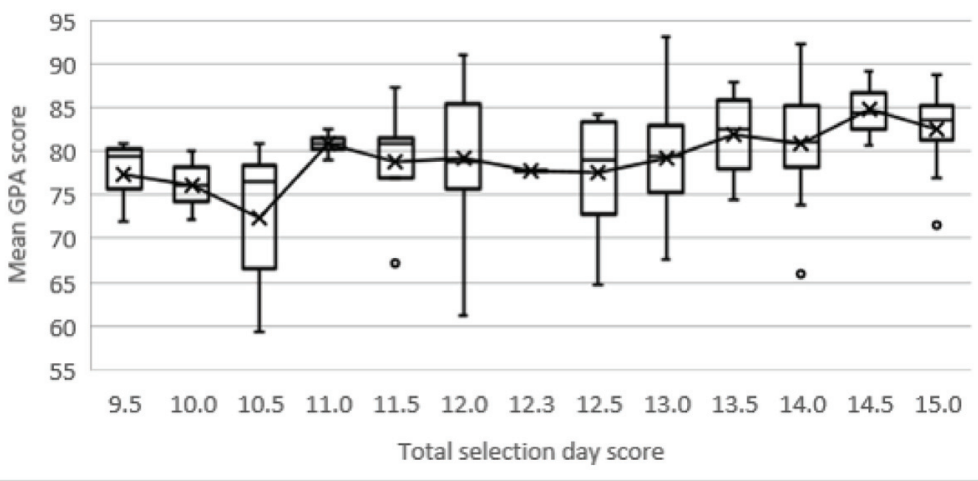

Figure 2. Mean GPA score for the eight Year 1 courses as a function of the total selection day score, excluding dropouts.

course grades are significant, most at $p<0.01$ or lesser. Therefore, in order to clearly demonstrate the correlation between SD scores and grades (when all courses are completed), we need to remove the effect of intake date.

Table 8 above uses SPSS's partial correlation procedure to remove the effects of intake date on the correlations between SD scores and course grades. It shows that the total SD score is correlated significantly with the Year
One mean grade, the two semester means, and grades for five courses. The total score correlation is significant only where course correlations are significant. The writing task results are identical except for a lower level significance for the Year One mean grade and one fewer course correlation. Interview scores are significantly correlated with grades for one course, and with the mean grade for semester one. The team activity scores have no significant correlations with grades.

The final step in our analysis is to determine the effect size and practical consequences of significant SD score correlations. Lenhard and Lenhard (2016) categorise the effect size of correlations as follows: small, $r=0.10-0.22$; moderate, $r=0.23-0.35$; and large, $r=0.36-0.45$. Of the significant correlations in Table 8, 25\% are small, 69\% are moderate (including the mean Year One/ total score correlation) and one $(6 \%)$ is large. The box and whisker plot in Figure 2 shows the relationship between mean GPA scores and total intake scores, demonstrating the variability in the data which characterises a moderate effect size. Low total intake scores (9.5-10.5) average in the $\mathrm{B}$ to $\mathrm{B}+$ range, mid-range scores (11.5-13.0) average $\mathrm{B}+$ and 
the highest scores (13.5-15.0) average A-. Thus, while the correlations demonstrate an effect of moderate power for SD scores, the consequences in terms of GPA operate within a narrow (5 to 10-point) range and thus have little practical effect.

\section{Limitations of the study}

A limitation of the present study is the nonstandardised nature of the scoring process for SD tasks. Although a moderation process is in place - and final decisions are made at a team review meeting, which mitigates assessor subjectivity (Watson, 2002) - the criteria for marking are inherently subjective and, inevitably, different markers are used for different selection days. Also, staff have a bias towards scoring high, particularly on the team activity and interview tasks, assigning low scores mostly to applicants who perform very poorly. The median scores show that over $50 \%$ of applicants received the maximum mark in the team exercise, and over 4.5 in the interview. However, in the writing task and total scores, the median is well below the maximum, indicating a reasonable degree of discrimination in scoring.

Inconsistent scoring processes are most apparent when we examine mean writing scores (see Table 7) across intake dates in relation to student grades achieved. The November 2011 and top-up intake groups evidence the highest writing scores, yet the November 2012 group achieved the highest GPAs (79.8, 77.4, and 81.5, respectively).

\section{Conclusions}

The aim of this research was to determine whether selection tasks for the Bachelor of Social Practice degree at Unitec in Auckland, Aotearoa New Zealand are correlated with student success in the programme. The findings show that, while the total selection score achieved and performance on the written task, in particular, do influence how well students will perform in the programme when they complete all (compulsory) first-year courses, they do so only to a moderate degree and they do not predict whether students will fail to complete one or more courses. The latter finding is particularly striking given our relatively large $(N=196)$ and diverse sample size, and the large number of students who did not complete one or more courses (79). Notably, the vast majority of students who fail do not complete.

We have shown that there are inconsistencies in the application of selection measures across BSP degree intakes, and some limitations in the scoring of the interview and team activity in particular. Given that the latter are shown to have little or no correlation with course grades, respectively, these limitations may well have affected our results. That said, these tools are inherently open to bias and difficult to improve in this respect (Ross, 2010; Watson, 2002), though admittedly research on this topic is very sparse (Hughes et al., 2016).

Overall, this case study confirms previous research suggesting that selection tools generally speaking are flawed and unreliable predictors of student success in social work programmes (Hughes et al., 2016; Poole et al., 2012; Ryan, Cleak, \& McCormack, 2006). This study also fills a gap in the literature by exploring the value of specific selection tools and measures (Hughes et al., 2016) in this case in relationship to students' results in eight core courses. While the written task and its selection suite as a whole do appear to have some (limited) discriminating value, the interview and especially the team activity are clearly ineffective measures of how well students will do in the BSP programme, although they may be effective screening devices for excluding unsuitable applicants (a topic which the current study does not accommodate). As Sowbel (2012) notes, a gatekeeping role on admission is an ethical obligation to protect future clients. It also embodies an obligation to students who may not be able to engage a fieldwork placement or secure employment after graduating (due to certain criminal convictions, for example). 
However, this gatekeeping function can be part of a less resource-intensive selection process, potentially (pending future research) with selection tools that are more effective than the ones currently in use in the BSP programme. Possible alternative tools include psychometric testing and the biographical questionnaire, both of which require further research to determine their effectiveness. The biographical questionnaire has been shown to have content validity, but its predictive validity in terms of student success is as yet unclear (Ross, 2010). Dillon (2007) suggests that psychometric testing allows for a relatively reliable identification of candidate traits that are more likely to predict success than a range of other selection measures. Harder measures such as GPAs from previous study are not recommended, because they "have been consistently shown ... to be unreliable predictors of student success" (Hughes et al., 2016, p. 104). In addition, although more objective selection measures are easily standardised, the way the results are used can be quite variable (Adam, Dowell, \& Greatrix, 1999).

As noted in the introduction to this article, harder measures have also been consistently shown to exclude suitable students from programmes (Hughes et al., 2016), a point which highlights a key issue raised in this article. It is important that any selection tool is used in such a way that guards against the exclusion of students who could be supported to do well in their studies, and to become appropriately fit and proper social work practitioners in the process. This issue is particularly important for a profession that espouses social justice, inclusion, and the possibility of transformative change (see Apaitia-Vague et al., 2011).

To eliminate their impacts on the question of whether selection tasks are correlated with student success, this study also examined whether a range of demographic factors are correlated with success. Three such factors were shown to do so, independently of each other. These are studying full time, wage-earning or self-employed status on admission, and/or admission during a November intake, the latter allowing a large time gap between admission and starting the BSP programme. Notably, employment status and full-time student status have no impact on degree of success for those who complete all courses; unlike performance on selection day tasks, they are correlated with the key success goal of course completion (and with this goal only).

Our findings speak to the value of supporting students to succeed during the course of their study, and raise caution around gatekeeping admission processes too strongly. Further research is needed to explore the significance of the demographic factors shown in the current project to correlate with success - factors which are beyond the scope of our research aim and are not normally considered in relation to student success and retention. We speculate that they are linked to being relatively wellresourced for study: via income support, contextual (e.g., family) support to study full time, and/or other forms of support in one's life allowing for advanced planning. Future research might investigate, for example, the importance of resource use during students' course of study, and of pastoral as well as life skills support to enable student success. This case study suggests that we should be especially mindful of applicants who perform poorly on selection day and might not be predicted to succeed in the programme, and yet might well succeed if provided with support along the way.

A focus on supporting students to succeed once they are admitted fits well with appropriate strategies surrounding the success and retention of Māori and Pacific students, two key priority groups within the New Zealand Government's Tertiary Education Strategy. As noted earlier in this paper, existing literature on Māori and Pacific student experiences and success in social work programmes focuses not on selection processes, but on student retention (as well as recruitment). Given new funding 
constraints for student loans coupled with pressure to increase enrolments, such a focus is also likely to benefit an increasing number of students within a diverse and inclusive student body.

\section{Note}

${ }^{1}$ One of the constraints noted in the government's analysis of the social work sector is the unknown quantity and nature of work being undertaken by social workers in non-government organisations (NGOs) (Ministry of Social Development, 2017).

\section{References}

Adam, J., Dowell, J., \& Greatrix, R. (1999). Use of UKCAT scores in student selection by UK medical schools, 2006-2010. BMC Medical Education, 11, 98-104.

Apaitia-Vague, T., Pitt, L., \& Younger, D. (2011). "Fit and proper" and fieldwork: A dilemma for social work educators? Aotearoa New Zealand Social Work Review, 23(4), 55-64.

Beddoe, L. (2007). Change, complexity and challenge in social work education in Aotearoa New Zealand. Australian Social Work, 60(1), 46-55.

Beddoe, L. (2014). A matter of degrees: The role of education in the professionalisation journey of social work in New Zealand. Aotearoa New Zealand Social Work Review, 26(2/3), 17-28.

Cornelissen, J. J., \& van Wyk, A. S. (2007). Professional socialisation: An influence on professional development and role definition. South African Journal of Higher Education, 21(7), 826-841.

Curtis, E., Wikaire, E., Stokes, K., \& Reid, P. (2012). Addressing indigenous health workforce inequities: A literature review exploring "best" practice for recruitment into tertiary health programmes. Journal for Equity in Health, 11(13). Retrieved from http://www.equityhealthj.com/content/11/1/13

Dillon, J. (2007). The conundrum of balancing widening participation with the selection of suitable students for social work education. Social Work Education, 26(8), 827-841.

Greenwood, J., \& Te Aika, L. (2009). Hei Tauira: Teaching and learning success for Māori in tertiary settings. Summary document, Wellington, NZ: Ako AotearoaThe National Centre for Tertiary Teaching Excellence.

Horrocks, J., Ballantyne, N., Silao, A., Manueli, K., \& Fairbrother, P. (2012). Success for Pacific learners: The impact of tertiary education strategies. Retrieved from https://akoaotearoa.ac.nz/download/ng/file/ group-5331/success-for-pacific-learners-the-impact-oftertiary-education-strategies.pdf

Hughes, C., McNabb, D., Ashley, P., McKechnie, R., \& Gremillion, H. (2016). Selection of social work students: A literature review of selection criteria and process effectiveness. Advances in Social Work and Welfare Education, 18(2), 94-106.

Lenhard, W., \& Lenhard, A. (2016). Calculation of effect sizes. Retrieved from https://www.psychometrica.de/ effect_size.html Bibergau (Germany): Psychometrica. doi:10.13140/RG.2.1.3478.4245
Madjar, I., McKinley, E., Jensen, S., \& Van Der Merwe, A. (2009). Towards university: Navigating NCEA course choices in low-mid decile schools. Auckland, NZ: Starpath Project, The University of Auckland.

McNabb, D. (2014). 30 years' membership and a 50th birthday - where to next for ANZASW? Aotearoa New Zealand Social Work Review, 26(2\&3), 61-71.

Ministry of Education. (2009). Motivation and achievement at secondary school: The relationship between NCEA design and student motivation and achievement: A three-year follow-up. Retrieved from https://www.educationcounts. govt.nz/_data/assets/pdf_file/0011/49358/NCEA Summary_Report_Final_150709.pdf

Ministry of Education. (2013). Ka Hikitia: Accelerating success / Māori education strategy 2013-2017. Wellington, NZ: Author

Ministry of Education. (2017). Participation rates in tertiary education. Retrieved from http://www.educationcounts govt.nz/statistics/indicators/main/student-engagementparticipation/1963.

Ministry of Social Development. (2013). Studylink News: A resource for education providers and student associations. Retrieved from https://www.providers. studylink.govt.nz/documents/studylink-news-2013-06.pdf

Ministry of Social Development. (2017). Regulatory impact statement: Legislative changes to increase the professionalism of the social work workforce. Retrieved from http://www.treasury.govt.nz/publications/ informationreleases/ris/pdfs/ris-msd-lgt-jul17.pdf

Ministry of Education, and the Ministry of Business, Innovation and Employment (2014). Tertiary education strategy 2014-2019. Retrieved from https://education. govt.nz/assets/Documents/Further-education/TertiaryEducation-Strategy.pdf

Nash, M. (2003). Social work education: Agencies and academic disciplines. International Social Work, 46(1), 23-35.

Office of the Minister for Social Development. (2017). Increasing the professionalism of the social work workforce. Cabinet Social Policy Committee proposal May 2017. Retrieved from https://www.msd.govt.nz/ documents/about-msd-and-our-work/publicationsresources/regulatory-impact-statements/2017.05.12swra-cabinet-paper-for-cabinet.pdf

Pelech, W., Stalker, C., Regehr, C., \& Jacobs, M. (1999). Making the grade: The quest for validity in admissions decisions. Journal of Social Work Education, 35(2), 215-226.

Poole, P., Shulruf, B., Harley, B., Monigatti, J., Barrow, M., Reid, P., . . Bagg, W. (2012). Shedding light on the decision to retain an interview for medical student selection. New Zealand Medical Journal, 125(1361), 81-88.

Ross, E. (2010). Selection tests and social justice: A profile of applicants seeking admission to the social work undergraduate degree at a South African University. Social Work Education, 29(5), 459-474. doi:10.1080/0215470903177630

Ryan, M., Cleak, H., \& McCormack, J. (2006). Student performance in field education placements: The findings of a 6-year Australian study of Admissions Data. Journal of Social Work Education 42(1), 66-84. 


\section{ORIGINAL ARTICLE}

Social Workers Registration Board (SWRB). (2013). The process for recognition/re-recognition of social work qualifications in New Zealand. Wellington, NZ: Author.

Social Workers Registration Board. (2015). Fit and proper person: Policy statement. Retrieved from file:///C:/Users/ Catherine/Downloads/Fit-and-Proper-Policy\%20(1).pdf

Social Workers Registration Board. (2015-16) Annual report. Retrieved from http://www.swrb.govt.nz/news-andpublications/publications

Social Services Committee. (2016). Inquiry into the operation of the Social Workers Registration Act 2003. Presented to the House of Representatives, December 2016. Retrieved From https://www.parliament.nz/ resource/en-NZ/51DBSCH_SCR71955_1/ 170b828c8c569c2b9b33e5dc08749ee79df34450

Social Practice PER. (2015). Programme evaluation and review for Unitec: Semester 1 and 2, 2014. Auckland, NZ: Author.

Sowbel, L. (2012). Gatekeeping: Why shouldn't we be ambivalent? Journal of social Work Education, 48(1), 27-44.

Watson, D. (2002). Just a paper exercise? Social Work Education, 21(1), 79-89 